\title{
Aortic root remodeling and valve sparing "new-old" technique
}

\begin{abstract}
Objectives: Different surgical approaches have been suggested for aortic root aneurysm repair. We have developed our technique of aortic root remodeling, based on the plication of the wall of the sinuses of Valsalva and sinotubular junction, and covering the aortic root with tree patches in bovine pericardium.
\end{abstract}

\section{Methods}

Operative procedure: Aorta is resected above the sinotubular junction. The sinuses of Valsalva and the sinotubular junction are plicated. Three patches in bovine pericardium (one for each sinus) are used to cover the aortic root. The patches are fixed to the annulus by three sub annular stitches placed under the nadir of the commissures. The distal end of these patches are fixed at the level of sinotubular junction between one another and commissural aortic wall.

Results: From January 2000 to February 2011130 patients underwent this operation. There were two hospital deaths. Aortic valve insufficiency was not significant in all but four patients for severe aortic insufficiency required aortic valve replacement during the procedure. In the follow up no significant enlargement of the aortic root was detected. Three patients were reoperated for aortic valve replacement.

Conclusion: With our technique, we remodel the sinuses of Valsalva and sinotubular junction to achieve the normal functioning of the aortic valve, by fixing the aortic annulus and covering the aortic root with three patches of bovine pericardium. We have found advantages in our new method compared with valve sparing and Florida Sleeve procedures.

\author{
Volume I Issue 7 - 2014
}

\author{
Salvatore Spagnolo,' Paata Kalandadze,' \\ Vincenzo Arone,' Maria Antonietta Grasso ${ }^{2}$ \\ 'Division of Cardiac Surgery, Policlinic of Monza, Italy \\ ${ }^{2}$ Division of Cardiovascular Anesthesia and Intensive Care, \\ Policlinic of Monza, Italy
}

Correspondence: Paata Kalandadze, Division of Cardiac Surgery, Policlinico di Monza, via Amati I I I, Monza (20052), Italy, Tel 39-039-28I0362, Fax 39-035-0779235,

Email buka@fastwebnet.it

Received: November 24, 2014 | Published: December 24, 2014

Keywords: valve sparing, aortic root, aortic ectasia

\section{Introduction}

Forty years ago, Bentall and De Bono ${ }^{1}$ described a technique for composite aortic valve and root replacement with reimplantation of the coronary arteries. For many years, this operation was the only option for patients with aneurysm of the ascending aorta. In the mid 1990s Yacoub and David independently developed techniques for valve sparing approach with the goal of preserving morphologically intact cusps of the aortic valve. ${ }^{2-7}$ In valve sparing surgery preservation of the sinuses of Valsalva which reduces the cusp stress and prevention of dilatation of the aortic annulus are both necessary to obtain long term durability. In last 10years "Florida Sleeve" repair become increasingly popular, ${ }^{8,9}$ even if this technique was first published by Ergin and Griepp. ${ }^{10}$ This procedure is more simple and could avoid valve degeneration or annulus dilatation, but it has yet to be established whether this procedure is suitable for patients with specific indications or it is more widely applicable.

We developed our own technique for aortic root repair. Even if this procedure was used for aortic dissection and first published in 1984 by Spagnolo et al., ${ }^{11}$ This operation was based on 3 steps: annulus reduction, valve sparing and reinforcement of the aortic root by Dacron patch. Unfortunately the publication was not considered and for many years remains unknown for international audience. Our operation is an alternative to valve sparing and Florida Sleeve operations. This technique allows to repair the sinuses of Valsalva and sinotubular junction, and to stabilize the aortic annulus and aortic root. There is no need for graft sizing and the learning curve for this type of operation is not significant.

\section{Materials and methods}

Since January 2000, 130 patients with aortic root aneurysm have been operated using our aortic root remodeling technique. Patients mean age was 65 , 4years. 127 patients were suffering from aortic root ectasia and three patients had acute aortic dissection. Table 1 shows the clinical profile of the patients. As shown in Table 1 there was significant dilatation of the sinuses of Valsalva and sinotubular junction, which causes severe aortic insufficiency in 12 patients, moderate in 58, mild in 60 and trivial in 11 patients.

Table I Patient characteristics

\begin{tabular}{ll}
\hline Number fo patients & 130 \\
Mean age (years) & $65,4(29-84)$ \\
Male/Female & $80 / 50$ \\
Aortic ectasia & 127 \\
Marfan & 0 \\
Aortic dissection & 3 \\
Bicuspid valve & 0 \\
LVEF(\%) & $60.5 \pm 6.8$ \\
Annulus diameter (mm) & $25.2 \pm 3.8$ \\
Sinuses diameter (mm) & $52.4 \pm 4.5$ \\
STJ diameter (mm) & $43.3 \pm 4.3$ \\
Aortic insufficiency (AOI) severe & 12 \\
Ao I moderate & 58 \\
Ao I mild & 60 \\
Ao I trivial & $\mathrm{II}$ \\
\hline
\end{tabular}

\section{Operative procedure}

The patient is monitored with TEE. A standard sternotomy is performed. The arterial cannulation site can be the distal ascending 
aorta or rarely the femoral artery, depending on the extent of the ascending aortic resection. Venous drainage is provided using a single cannula, unless surgical maneuvers are required on the mitral or tricuspid valves. The heart is arrested in diastole using $750 \mathrm{cc}$ of integrate cold blood hyperkalemic cardioplegia. Cardiac arrest is maintained during the operation using cold blood retrograde cardioplegia delivered through a coronary sinus catheter. The aorta is transected distal to the sinotubular junction. The right and left coronary arteries are identified for the underlying tissues (Figure 1). Separation of the right ventricular fibers from the left ventricular outflow tract, at the level of the right commissure, is then performed, to allow the placement of the sub annular stitches later in the procedure. Then the aortic valve is inspected, assessing the thickness and coaptation of the leaflets and prolapse of the cusps. If the leaflets appeared morphologically normal, aortic root remodeling is performed. Our technique consists of four steps: 1. Remodeling of the valsalva sinuses: Mean diameter of the sinuses in our series was $52,4 \mathrm{~mm}$. In the largest number of patients the only dilatation of the non-coronary sinus is present, that is why reduction of the non coronary sinus by resection or plication is enough in most cases (Figure 2).

2. Reduction of STJ: In all cases, sinotubular junction was dilated and the mean diameter was $43,3 \mathrm{~mm}$, causing different grade of aortic insufficiency. Plication of the sinotubular junction must be done after measuring the diameter of the aortic annulus. The size of sinotubular junction after the plication must be $15-20 \%$ less than the aortic annulus diameter (Figure $3 \& 4$ )

3. Stabilization of the aortic annulus: The majority of our patients has mild dilatation of the aortic annulus. In our series, the mean annulus diameter was $25,2 \mathrm{~mm}$. Three 2.0 Ethibond pledgeted mattress sutures are placed from the ventricular to the aortic outside in the subannular subcommissural triangles (under the nadir of each commissure) in order to fix the diameter of the annulus (Figure 5).

Table 2 Postoperative complications

\begin{tabular}{lll}
\hline Variable & $\mathbf{n}$ & $\%$ \\
\hline Hospital deaths & 2 & I.5 \\
Low cardiac output & $\mathrm{I}$ & 0.7 \\
Bleeding & 5 & 3.8 \\
Aortic insufficiency & 4 & 3.0 \\
TIA & 4 & 3.0 \\
Sternal infection & 4 & 3.0 \\
Endocarditis & $\mathrm{I}$ & 0.7 \\
Permanent pace-maker & 2 & 1.5 \\
Atrail filtration & 30 & 23 \\
Prolonged Ventilation & 5 & 3.8 \\
Pneumonia & 3 & 2.3 \\
Renal complications & 3 & 2.3 \\
\hline
\end{tabular}

Table 3 Results after operation and at follow - up (6.4 years)

\begin{tabular}{lll}
\hline Pts n I24* & Post-op & Follow up \\
\hline Aol severe or moderate & 0 & $3 * *$ \\
Ao I mild & 3 & 10 \\
Annulus diameter $(\mathrm{mm})$ & $24.8 \pm 2.4$ & $24.3 \pm 2.2$ \\
Valsalva diameter $(\mathrm{mm})$ & $38.7 \pm 3.2$ & $38.3 \pm 4.2$ \\
STJ diameter $(\mathrm{mm})$ & $26.3 \pm 3.0$ & $25.5 \pm 5.2$ \\
EF $(\%)$ & $55.7 \pm 7.6$ & $62.6 \pm 4.3$ \\
\hline
\end{tabular}

*From I 30 patients remains I 24 (2 death and 4 aortic valve replacement)

**3 patients were re-operated for aortic valve replacement

Covering of the aortic root with three patches in bovine pericardium Three pericardial patches (one for each sinus) are fixed to the annulus by three subannular stitches, placed under each commissure. The patches are fixed to one another with the same subannular stitch. The distal end of these patches are fixed at the level of sinotubular junction between one another and with commissural aortic wall (Figure 6) (Figure $4 \& 7$ ) creating a periaortic wall of the aortic root. The patches are incised over the left and right coronary arteries not to cause compression. Direct end-to-end anastomosis between neo aortic root and ascending aorta is then performed.

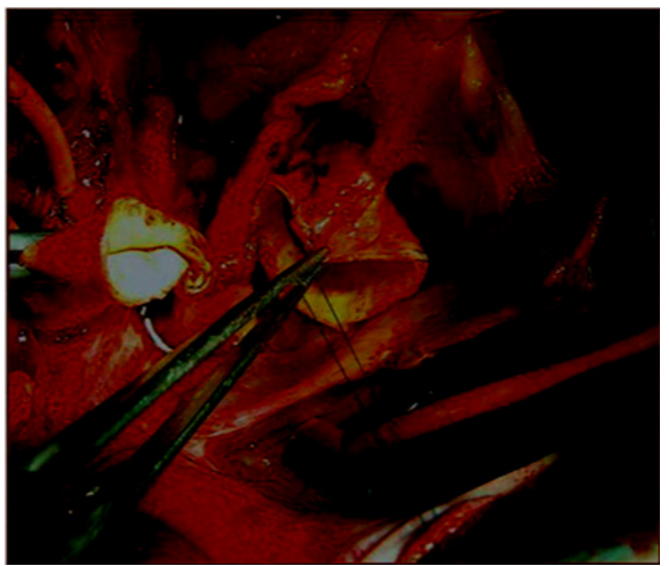

Figure I The right and left coronary arteries are identified for the underlying tissues.

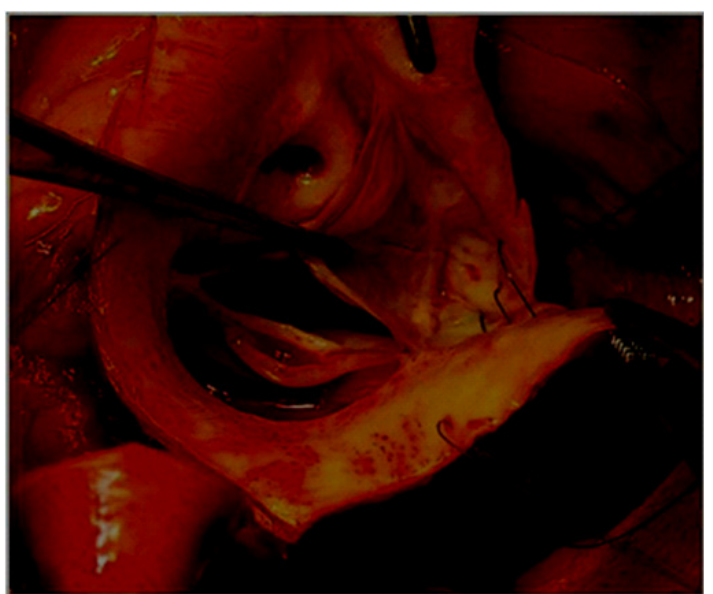

Figure 2 Resection of the non coronary sinus.

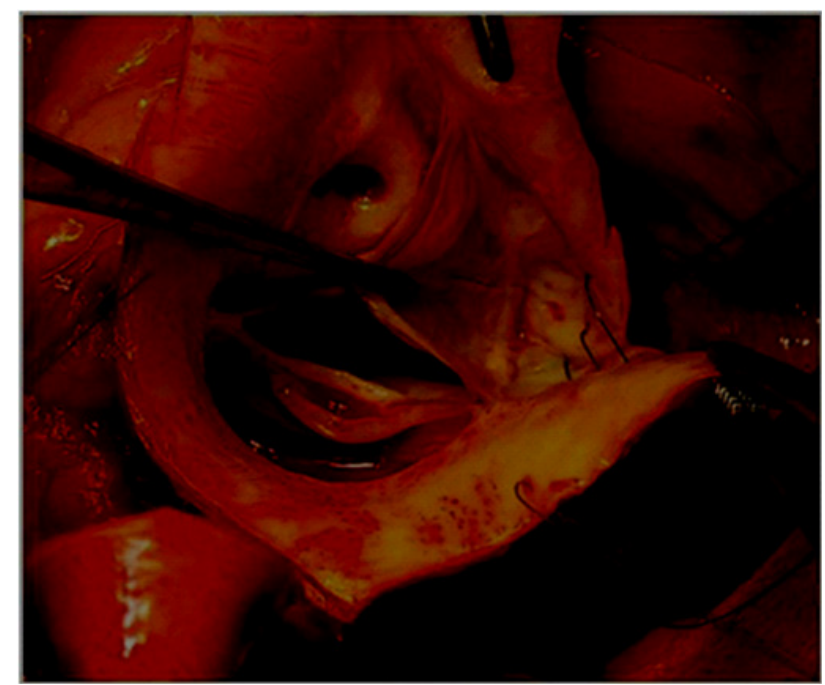

Figure 3 Plication of the sinotubular junction. 


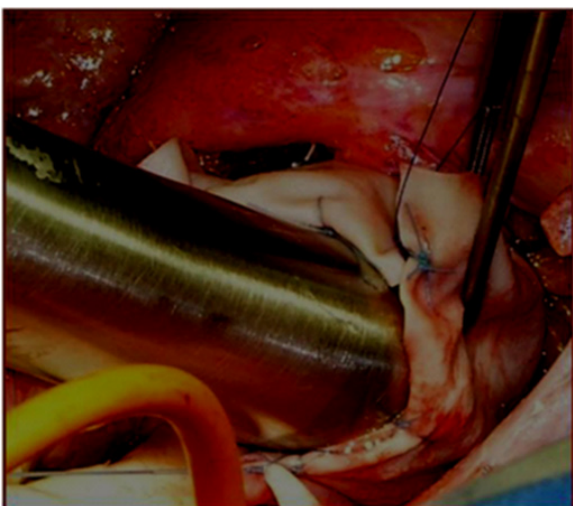

Figure 4 The size of sinotubular junction after the plication must be I5-20\% less than the aortic annulus diameter.

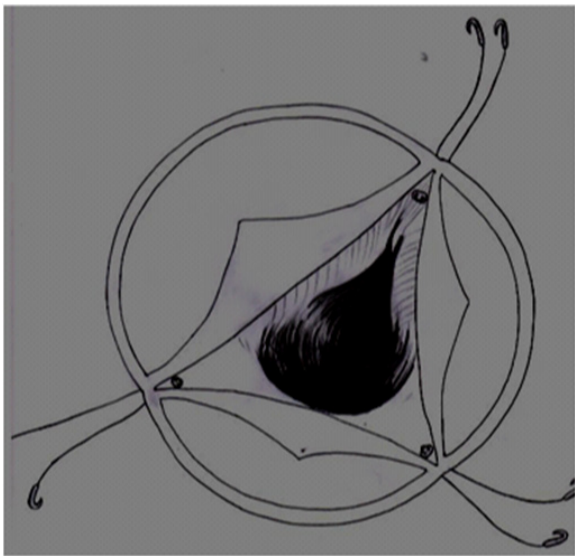

Figure 5 Three 2.0 Ethibond pledgeted mattress sutures are placed from the ventricular to the aortic aspect in the subannular subcommissural triangles (under the nadir of each commissure) in order to fix the diameter of the annulus.

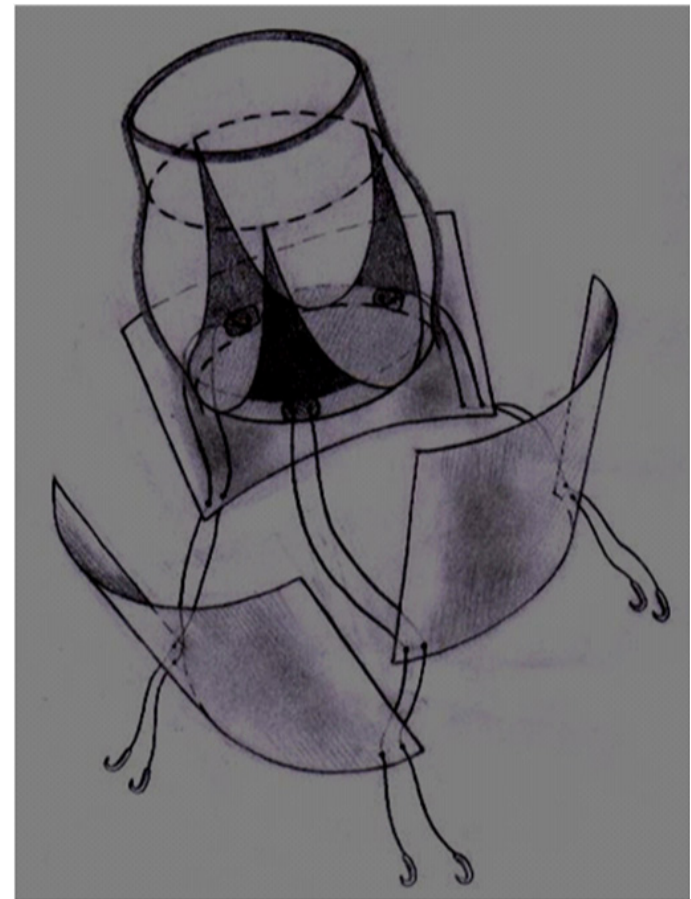

Figure 6 Covering of the aortic root wall with three patches in bovine pericardium.

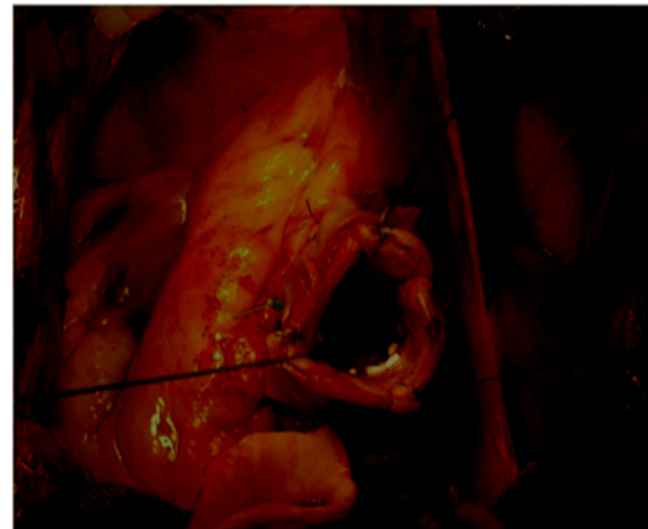

Figure 7 Covering of the aortic root with three patches in bovine pericardium.

\section{Results}

\section{Short-term and mid-term outcome}

In the 130 patients operated, there were two hospital deaths, one for low cardiac output and another for gastric complications and multi organ failure. Four patients suffered a stroke with complete recovery. Five patients required reoperation for bleeding. There were no coronary complications. Aortic valve insufficiency was not significant in all but in four patients severe aortic insufficiency was detected by TEE in operating room and in these patients aortic valve was replaced during the same operation. Operative results are shown in (Table 2).

No enlargement of the aortic annulus, sinuses of Valsalva or sinotubular junction were detected during the follow-up (mean 6,4years). Three patients were reoperated for aortic valve insufficiency. Post operative and follow up results are shown in (Table 3 ).

\section{Comment}

Various techniques have been developed for aortic root reconstruction. Bentall operation was used for many years. For 20 years, valve sparing operations are valid alternative of Bentall procedure. Valve sparing operations are technically demanding with a small margin of error, both techniques needs coronary reimplantation and aortic root replacement by prosthetic material. Recent publications regarding valve sparing procedures show a trend toward the reimplantation rather than to remodeling technique, because this technique allows stabilization of the annulus. Although reimplantation technique seems to achieve more satisfactory results, according to some authors, it damages the sinus of Valsalva and in long times also the aortic valve. ${ }^{12-17}$ In last 10years "Florida Sleeve" operation is becoming popular. Florida Sleeve procedure is easily reproducible and may represent an improvement in aortic root surgery in terms of annulus stability and aortic valve durability. Florida Sleeve procedure seems to be a good alternative to valve sparing operations but its validity needs to be verified by follow up. ${ }^{18}$

We described ourtechnique for the first timein $1989^{19}$. This procedure is very similar to the Florida Sleeve one, but with some differences: 1. In Florida Sleeve procedure, the native root remains untreated, that is the sinuses of Valsalva and sinotubular junction are not plicated.

\section{The aortic root is wrapped with a Dacron tube.}

In our operation, we are remodeling the aortic root in order to obtain normal sized aortic root and sinotubular junction and to ensure aortic valve competence, simply shaping each sinus in the right size 
and covering neo aortic root with tree patches in bovine pericardium. We are using bovine pericardium instead of Dacron graft because we believe that there is less tissue stress between bovine pericardium and aortic wall rather than between Dacron and aortic wall.

\section{Conclusion}

For the patients with aortic root ectasia this operation is a good alternative to Florida Sleeve procedure. Our technique is simple to perform and it gives the possibility to achieve the remodeling of the native aortic root and the stabilization of the valvular annulus and aortic root, by covering the aortic root with pericardial patches. Initial results are satisfactory, showing aortic annulus and root stability. Long-term follow up is necessary to check its validity.

\section{Acknowledgments}

None.

\section{Conflicts of interest}

Author declares there are no conflicts of interest.

\section{Funding}

None.

\section{References}

1. Bentall H, De Bono A. A technique for complete replacement of the ascending aorta. Thorax. 1968;23(4):338-339.

2. David TE, Feindel CM. An aortic valve-sparing operation for patients with aortic incompetence and aneurysm of the ascending aorta. J Thorac Cardiovasc Surg. 1992;103(4):617-622.

3. Sarsam MA, Yacoub M. Remodeling of the aortic valve annulus. $J$ Thorac Cardiovasc Surg. 1993;105(3):435-438.

4. Pepper J, Yaacoub M. Valve conserving operation for aortic for aortic regurgitation. J card Surg . 1997;12(2 Suppl):151-156.

5. Birks EJ, Webb C, Child A, et al. Early and long term results of a valve sparing operation for Marfan syndrome. Circulation. 1999;100(19 Suppl):II29-II35.

6. David TE, Feindel CM, Bos J. Repair of the aortic valve in patients with aortic insufficiency and aortic root aneurysm. J Thorac Cardiovasc Surg. $1995 ; 109(2): 345-351$
7. David TE, Armstrong S, Ivanov J, et al. Results of valve sparing operations. J Thorac Cardiovasc Surg. 2011;122(1):39-46.

8. Hess PJ, Klodell CT, Beaver TM, et al. The Florida sleeve: a new technique for aortic root remodeling with preservation of the aortic valve and sinuses. Ann Thorac Surg. 2005;80(2):748-750.

9. Komoda T, Klomoda S, Gehle P, et al. Reverse graft placement in the Florida sleeve procedure for aortic root aneurysm. Ann Thorac Surg. 2013;95(2):723-725

10. Ergin MA, Griepp RB. When, why and how should native aortic valve be preserved in patients with annuloaortic ectasia or Marfan syndrome. Semin Thorac Cardiovasc Surg. 1993;5(1):91-92.

11. Spagnolo S, Dottori V, Micolizzi E, et al. La dissezione acuta dell'aorta toracica Proposta di una nuova technica chirurgica. Cardiol. 1984;14(11):1113-1117.

12. Leyh RG, Schmidtke C, Sievers HH, et al. Opening and closing characteristics of the aortic valve after different types of valve-preserving surgery. Circulation. 1999;100(21):2153-2160.

13. David TE, Feindel CM, Webb GD, et al. Aortic valve preservation in patients with aortic root aneurysm: results of the reimplantation technique. Ann Thorac Surg. 2007;83(2):S732- S735.

14. David TE, Ivanov JI, Armstrong S, et al. Aortic valve-sparing operations with aneurysm of the aortic root or ascending aorta. Ann Thorac Surg. 2002; 74(5): 1758-1761.

15. Hagl C, Strauch JT, Spielvogel D, et al. Is the Bentall procedure for ascending aorta or aortic valve replacement the best approach for longterm event-free survival. Ann Thorac Surg. 2003;76(3):698-703.

16. Albes JM, Stock UA, Hartrumpf M. Restitution of the aortic valve: what is new, what is proven, and what is obsolete? Ann. Thorac Surg. 2005;80(4):1540-1549.

17. Schäfers H, Fries R, Langer F, et al. Valve preserving replacement of the ascending aorta-remodeling vs. Reimplantation. J Thorac Cardiovasc Surg. 1998;116(6):990-996.

18. Hess PJ Jr, Klodell CT, Beaver TM, et al. Early outcomes using the Florida sleeve repair for correction of aortic insufficiency due to root aneurysms. Ann Thorac Surg. 2009;87(4):1161-1168.

19. Giambuzzi M, Spagnolo S, Dottori V, ET AL. Aortic valve reconstruction associated to assending aorta tubular graft replacement in aortic incompetence by annuloaortic ectasia. Eur J Cardiothorac Surg. $1998 ; 14(2): 148-151$ 